\title{
Aberrant promoter methylation of multiple genes in VSMC proliferation induced by Hcy
}

\author{
SHENG-CHAO MA $^{1 *}$, JIAN-CHENG CAO ${ }^{1 *}$, HUI-PING ZHANG ${ }^{2}$, YUN JIAO $^{3}$, HUI ZHANG ${ }^{1}$, YANG-YANG HE ${ }^{1}$, \\ YAN-HUA WANG ${ }^{1}$, XIAO-LING YANG ${ }^{1}$, AN-NING YANG $^{1}$, JUE TIAN $^{1}$, MING-HAO ZHANG $^{1}$, \\ XIAO-MING YANG ${ }^{1}$, GUAN-JUN LU ${ }^{4}$, SHAO-JU JIN ${ }^{1}$, YUE-XIA JIA ${ }^{1}$ and YI-DENG JIANG ${ }^{1}$ \\ ${ }^{1}$ School of Basic Medical Sciences, Ningxia Medical University; Departments of ${ }^{2}$ Prenatal Diagnosis Center, \\ ${ }^{3}$ Infectious Disease and ${ }^{4}$ Urinary Surgery, General Hospital of Ningxia Medical University, \\ Yinchuan, Ningxia 750004, P.R. China
}

Received July 28, 2016; Accepted August 10, 2017

DOI: $10.3892 / \mathrm{mmr} .2017 .7521$

\begin{abstract}
Vascular smooth muscle cell (VSMC) proliferation is a primary pathological event in atherosclerosis (AS), and homocysteine (Hcy) is an independent risk factor for AS. However, the underlying mechanisms are still lagging. Studies have used the combination of methylation of promoters of multiple genes to diagnose tumors, thus the aim of the current study was to investigate the role of methylation status of several genes in VSMCs treated with Hcy. CpG islands were identified in the promoters of platelet-derived growth factor (PDGF), p53, phosphatase and tensin homologue on chromosome 10 (PTEN) and mitofusin 2 (MFN2). Hypomethylation was observed to occur in the promoter region of PDGF, hypermethylation in p53, PTEN and MFN2, and hypomethylation in two global methylation indicators, aluminium (Alu) and long interspersed nucleotide element-1 (Line-1). This was accompanied by an increase in the expression of PDGF, and reductions of p53, PTEN and MFN2, both in mRNA and protein levels. An elevation of S-adenosylmethionine (SAM) and a reduction of S-adenosylhomocysteine (SAH) and the SAM/SAH ratio were also identified. In conclusion, Hcy impacted methylation the of AS-associated genes and global methylation status that mediate the cell proliferation, which may be a character of VSMCs treated with Hcy. The data provided evidence for mechanisms of VSMCs proliferation in AS induced by Hcy and may provide a new perspective for AS induced by Hcy.
\end{abstract}

Correspondence to: Professor Yi-Deng Jiang, School of Basic Medical Sciences, Ningxia Medical University, 1160 Shengli Street, Yinchuan, Ningxia 750004, P.R. China

E-mail: jydcan@126.com

\section{*Contributed equally}

Key words: homocysteine, DNA methylation, vascular smooth muscle cells, atherosclerosis

\section{Introduction}

Previous studies have demonstrated that elevated levels of homocysteine (Hcy) have been implicated as an independent risk factor for atherosclerosis (AS) (1-3). Studies have focused on the involvement of Hcy on the dysfunction and injury of vascular cells, such as vascular smooth muscle cells (VSMCs) $(4,5)$. It has been previously observed that Hcy induced VSMCs proliferation, however the underlying mechanisms remain to be fully elucidated (6).

Hcy is a non-protein, sulfur containing amino acid, which is a metabolic intermediate of the methionine cycle. It is a precursor of S-adenosylmethionine (SAM), the unique methyl group donor for DNA methylation (7). Subsequent to transfer of the methyl group, SAM is transformed into S-adenosylhomocysteine (SAH), which can be hydrolyzed to form Hcy (8). DNA methylation refers to the addition of a methyl group to the 5 position of cytosine in the context of a $\mathrm{CpG}$ dinucleotide. Increasing evidence indicates that human diseases, including AS, are either caused or impacted by abnormal methylation (9). A previous study suggested that Hcy may also be involved in disturbing the expression of AS-associated genes through the interference of DNA epigenetic phenotype modification, such as DNA methylation (10). An additional previous study demonstrated that abnormal DNA methylation of genes including peroxisome proliferator-activated receptor $\alpha$, apolipoprotein E (ApoE) and genomic DNA contribute to the development of AS induced by Hcy $(11,12)$. Studies have identified DNA methylation profiling of the vascular tissues in the setting of AS or atherosclerotic plaques $(13,14)$. However, the methylation status of several key genes that characterized the VSMC proliferation induced by Hcy in single VSMCs remains to be elucidated. In addition, it remains unclear whether Hcy affected the methylation status and caused proliferation.

In the present study, platelet-derived growth factor (PDGF), p53, phosphatase and tensin homologue on chromosome 10 (PTEN) and mitofusin 2 (MFN2), which are associated with cell proliferation regulation, and two global methylation indicators, aluminium (Alu) and long interspersed nucleotide element-1 (Line-1) were selected to analyze the methylation 
status in the VSMCs treat with Hcy, which may clarify the mechanisms of VSMCs proliferation in AS induced by Hcy and provide a potential diagnostic marker for AS induced by Hcy.

\section{Materials and methods}

Cell culture. Primary culture of VSMCs was obtained from the media of the umbilical vein of human as previously described (15). Experiments were approved by the Ningxia Medical University Medical Ethical Committee (Yinchuan, China). Cells were cultured in Dulbecco's modified Eagle's medium-Han's F12 media (DMEM-F12; Gibco; Thermo Fisher Scientific, Inc., Waltham, MA, USA) supplemented with $20 \%$ fetal bovine serum (FBS; Gibco; Thermo Fisher Scientific, Inc.), $100 \mathrm{U} / \mathrm{ml}$ penicillin and $100 \mathrm{U} / \mathrm{ml}$ streptomycin (Gibco; Thermo Fisher Scientific, Inc.) at $37^{\circ} \mathrm{C}$ in an incubator with $5 \% \mathrm{CO}_{2}$. When cells grew to $80 \%$ confluence, serum was media-deprived for $24 \mathrm{~h}$ to become synchronous, then 5\% FBS (Gibco; Thermo Fisher Scientific, Inc.) for another $24 \mathrm{~h}$ before Hcy addition. Hcy was applied at the concentrations of 30,50, 100, 200 and $500 \mu \mathrm{M}$ folate (Sigma-Aldrich; Merck KGaA, Darmstadt, Germany), and $5 \mu \mathrm{M}$ 5-aza-2'-deoxycytidine (AZC; Sigma-Aldrich; Merck KGaA), respectively.

Nested methylation-specific-polymerase chain reaction (nMS-PCR) for methylation analysis. The detection of methylation levels was conducted as previously described (16). The summary of primers and product sizes of the nMS-PCR assays are presented in Table I.ThePCR products were separated by electrophoresis through a $2 \%$ agarose gel containing ethidium bromide. DNA bands were visualized by Gel Documentation and Analysis System ChemiDoc XRS (Bio-Rad Laboratories, Inc., Hercules, CA, USA) and calculated by the formula: Methylation $\%=$ methylation $/($ methylation + unmethylated $)$ $\mathrm{x} 100 \%$.

Reverse transcription-quantitative PCR (RT-qPCR) for measurement of $m R N A$ expression. The total RNA was isolated using TRIzol reagent (Invitrogen; Thermo Fisher Scientific, Inc.). And the RNA ( $2 \mathrm{ml})$ was reverse transcribed using the Revert Aid First Strand cDNA synthesis kit (Fermentas; Thermo Fisher Scientific, Inc., Pittsburgh, PA, USA) for $60 \mathrm{~min}$ at $42^{\circ} \mathrm{C}$ and $70^{\circ} \mathrm{C}$ for $5 \mathrm{~min}$. The primer nucleotide sequences of PDGF are as presented in Table II. The RT-qPCR was conducted with the FTC-3000 Real-Time PCR detection system (Funglyn Biotech, Inc., Toronto, ON, Canada). The qPCR reaction system as follows: $25 \mu \mathrm{l}$ 2X SYBR mixture, $1 \mu 1$ forward primer, $1 \mu 1$ reverse primer, $2 \mu \mathrm{l} \mathrm{cDNA}$ and then RNase-free water up to $50 \mu$ l. The thermocycling conditions were as follows: Initial activation at $95^{\circ} \mathrm{C}$ for $5 \mathrm{~min}$, followed by 30 cycles of $95^{\circ} \mathrm{C}$ for $20 \mathrm{sec}$, annealing temperatures for $20 \mathrm{sec}$ (as stated in Table II) and at $72^{\circ} \mathrm{C}$ for $30 \mathrm{sec}$. The mRNA level of each gene was acquired from the value of the quantification cycle (Cq) of the qPCR as associated to that of glyceraldehyde-3-phosphate dehydrogenase (GAPDH) using the following equation (17): $\Delta \mathrm{Cq}=\mathrm{Cq}_{(\mathrm{GAPDH})}-\mathrm{Cq}_{\text {(sample) }}$. Final results, expressed as $\mathrm{N}$-fold differences in the target gene expression and relative to the calibrator termed ' $\mathrm{N}_{\text {target }}$ ', were determined according to the following equation: $\mathrm{N}_{\text {target }}=2^{\mathrm{Cq}(\text { sample)-Cq(calibrator) }}$, where $\mathrm{Cq}$ values of the calibrator and sample were determined by subtracting the $\mathrm{Cq}$ value of the target gene from the Cq value. Each qPCR assay was performed in duplicate and included positive, negative and no template reagent controls.

Western blotting assay for measurement of proteins expression. Whole-cell proteins were extracted with cell lysis buffer (KeyGene, Shanghai, China) that included the protease inhibitor phenylmethanesulfonyl fluoride (KeyGene) at $4^{\circ} \mathrm{C}$ for $30 \mathrm{~min}$, then were separated by $12 \%$ sulfate-polyacrylamide gel electrophoresis. The proteins and the pre-stained marker (Fermentas; Thermo Fisher Scientific, Inc.) were then transferred onto an Immobilon-P transfer polyvinylidene fluoride membrane (EMD Millipore, Billerica, MA, USA) with a Semi-dry Transfer Cell (model 755; Bio-Rad Laboratories, Inc.) for $90 \mathrm{~min}$, allowing the pre-stained marker to be completely transferred from the gel to the membrane. The gel was then discarded and the membrane was incubated at room temperature in 5\% non-fat milk prepared with phosphate-buffered saline with $0.05 \% \mathrm{v} / \mathrm{v}$ Tween-20 (PBS-T) buffer. A total of $2 \mathrm{~h}$ later, the membrane was cut as required, placed in a suitable hybridization bag with $1 \mathrm{ml}$ of primary antibody [all primary antibodies were diluted to $1: 1,000$ with $1 \%$ non-fat milk; anti-PDGF (cat. no. ab23914), anti-p53 (cat. no. ab26), anti-PTEN (cat. no. ab32199), anti-MFN2 (cat. no. ab56889) and anti- $\beta$-actin (cat. no. ab8227) antibodies were obtained from Abcam, Cambridge, UK] and were incubated at $4^{\circ} \mathrm{C}$. The membrane was washed three times with PBS-T and the mouse anti-goat horseradish peroxidase-conjugated secondary antibody (cat. no. sc-2354; 1:2,000; Santa Cruz Biotechnology, Inc., Dallas, TX, USA) was added for $2 \mathrm{~h}$ at room temperature. Blots were developed on X-ray film (Kodak, Shanghai, China). The protein bands were visualized and analyzed using the Gel Documentation and Analysis System ChemiDoc XRS system with Image Lab software (version 4.1; Bio-Rad Laboratories, Inc.), and calculated by the gray value of the bands.

SAM and SAH concentrations examined by HPLC. The concentrations of SAM and SAH were determined by high performance liquid chromatography (HPLC). Samples were loaded into a C18 column (Shimadzu, Tokyo, Japan), run by a Hitachi L2000 HPLC system (HPLC; D-2000 Elite HPLC; Hitachi High Technologies, Tokyo, Japan). Absorption of eluted compounds was monitored at $(\lambda)$ ex $=254 \mathrm{~nm}$. Elution of SAM and SAH was achieved at a flow rate of $1.0 \mathrm{ml} / \mathrm{min}$ with the mobile phase ammonium format solution. Chromatograms were recorded using a D-2000 Elite integrator. SAM and SAH standards were used to identify the elution peaks, and the SAM and SAH values of the tissues were calculated with the standard curve.

Statistical analysis. Each experiment was repeated 3 times. Results were expressed as the mean \pm standard deviation. One-way analysis of variance was used to compare the means of multiple groups, followed by Newman-Keuls test. $\mathrm{P} \leq 0.05$ was considered to indicate a statistically significant difference.

\section{Results}

The bioinformatics analysis of promoters in PDGF, p53, PTEN and MFN2. As a key epigenetic modification of the genome, 
Table I. Summary of nested methylation-specific-polymerase chain reaction primers.

\begin{tabular}{|c|c|c|c|c|}
\hline Gene & $\begin{array}{l}\text { Forward primer } \\
\text { sequence }\left(5^{\prime} \rightarrow 3^{\prime}\right)\end{array}$ & $\begin{array}{l}\text { Reverse primer } \\
\text { sequence }\left(5^{\prime} \rightarrow 3^{\prime}\right)\end{array}$ & $\begin{array}{l}\text { Size } \\
\text { (bp) }\end{array}$ & $\begin{array}{c}\text { Annealing } \\
\text { temperature }\left({ }^{\circ} \mathrm{C}\right)\end{array}$ \\
\hline PDGF-O & AAGGTTGTTTTTATTTATTTTTTGT & AACTACAAACTACAACTACTCCAAT & 305 & 52 \\
\hline PDGF-M & GTTTGTTTGTTTTTTTGCGTATTC & CTACTCCGATTTTCTCTTTACAACG & 193 & 59 \\
\hline PDGF-U & GGTTTGTTTGTTTTTTTGTGTATTT & АСТССААТТТТСТСТТТАСААСААА & 192 & 57 \\
\hline p53-O & GTTTTGGTTTGAAGGATAGTAGTT & AAAAACCCTAAAACTTAATAAAAAC & 404 & 55 \\
\hline $\mathrm{p} 53-\mathrm{M}$ & TTAGTTTTAGTTAGGATGGTTTCGA & GAAAAATAAACCGAAATCCCG & 212 & 56 \\
\hline p53-U & ATTAGTTTTAGTTAGGATGGTTTTGA & CAAAAAATAAACCAAAATCCCAC & 214 & 55 \\
\hline PTEN-O & TTGGAAAGTTTTTTAATTAGGGATA & ATTTCAAAAACCCAAAAAACAC & 445 & 55 \\
\hline PTEN-M & GTGATTTTTTTCGGAAAGTAGTTTC & TAAAAACCCGACAAAATAAATCG & 211 & 57 \\
\hline PTEN-U & ATTTTTTTTGGAAAGTAGTTTTGA & AAAAACCCAACAAAATAAATCACC & 207 & 56 \\
\hline MFN2-O & ATAGAATGTAAATTTGGATTTTAGA & ACTAАТАAАСССТАААСССАACC & 355 & 53 \\
\hline MFN2-M & TTTGTTTCGTTTTTTTAGTTTCG & CTAAACCCAACCGACTCG & 210 & 55 \\
\hline MFN2-U & TTTGTTTTGTTTTTTTAGTTTTGG & TAAACCCAACCAACTCACC & 209 & 55 \\
\hline Alu-O & TATTTTGGTTAATAAGGTGAAATTT & TCCAACAACTATAAAAAAACTTTTT & 256 & 55 \\
\hline Alu-M & GGGCGTTTGTAGTTTTAGTTATTC & TAAAACGAAATCTCGCTCTATCG & 143 & 56 \\
\hline Alu-U & GGTGTTTGTAGTTTTAGTTATTTGG & TTAAAACAAAАTCTCACTCTATCACC & 143 & 56 \\
\hline Line-1-O & TTTATTAGGGAGTGTTAGATAGTGGG & TACCCAAACAAACCTAAACAATAAC & 359 & 57 \\
\hline Line-1-M & TATTAGGGAGTGTTAGATAGTGGGC & AACCCGATTTTCCAAATACGT & 162 & 59 \\
\hline Line-1-U & TTAGGGAGTGTTAGATAGTGGGTGT & AAAAAACCCAАTTTTCCAAАTACA & 164 & 59 \\
\hline
\end{tabular}

bp, base pairs; PDGF, platelet-derived growth factor; O, outer primers; M, methylated-specific primers; U, unmethylated-specific primers; PTEN, phosphatase and tensin homologue on chromosome 10; MFN2, mitofusin 2; Alu, aluminium; Line-1, long interspersed nucleotide element 1 .

Table II. Summary of reverse transcription-quantitative polymerase chain reaction primers.

\begin{tabular}{|c|c|c|c|c|}
\hline Gene & $\begin{array}{l}\text { Forward primer } \\
\text { sequence }\left(5^{\prime} \rightarrow 3^{\prime}\right)\end{array}$ & $\begin{array}{l}\text { Reverse primer } \\
\text { sequence }\left(5^{\prime} \rightarrow 3^{\prime}\right)\end{array}$ & Size (bp) & $\begin{array}{c}\text { Annealing } \\
\text { temperature }\left({ }^{\circ} \mathrm{C}\right)\end{array}$ \\
\hline PDGF & CCACTCGATCCGCTCCTTTGA & GAACCCAGGCTCCTTCTTCCAC & 150 & 60 \\
\hline p53 & CGTGTTTGTGCCTGTCCTG & TGCTCGCTTAGTGCTCCCT & 105 & 58 \\
\hline PTEN & AAGACCATAACCCACCACAGC & ACCAGTTCGTCCCTTTCCAG & 125 & 57 \\
\hline MFN2 & TACACTGGCTCCAACTGC & AACCAACCGGCTTTATTC & 188 & 55 \\
\hline
\end{tabular}

PDGF, platelet-derived growth factor; PTEN, phosphatase and tensin homologue on chromosome 10; MFN2, mitofusin 2; bp, base pairs.

DNA methylation occurs almost exclusively in the context of $\mathrm{CpG}$ dinucleotides, particularly in the $\mathrm{CpG}$ islands (18). Ranging from $0.5-5 \mathrm{~kb}$ and occurring on average every $100 \mathrm{~kb}$, $\mathrm{CpG}$ islands are $\mathrm{GC}$ rich (50-70\%) and have a ratio of $\mathrm{CpG}: \mathrm{GpC}$ of at least 0.6 (19). Collectively, CpG islands account for $1-2 \%$ of the genome and their location is primarily in the 5' regulatory regions of all housekeeping genes as well as up to $40 \%$ of tissue-specific genes (20). CpG methylation is associated with gene silencing, and to identify whether $\mathrm{CpG}$ islands exist in the chosen genes PDGF, p53, MFN2 and PTEN, the 5'-flanking region of the genes was analyzed using an online search engine (www.urogene.org/cgi-bin/methprimer/methprimer. cgi). The criteria of the $\mathrm{CpG}$ island is a $\mathrm{CpG}$-rich region length more than $100 \mathrm{bp}, \mathrm{GC}$ percentage $>50 \%$, and observe/expect ratio $>0.60$. As presented in Fig. 1, at least one $\mathrm{CpG}$ island was identified in the DNA promoter regions of all the 4 genes. In the PTEN gene promoter, $6 \mathrm{CpG}$ islands were observed, which indicated that they had greater potential to be modified by DNA methylation and regulated their expression.

PDGF, P53, PTEN, MFN2, Alu and line-1 methylation levels in VSMCs. To ascertain whether DNA methylation occurred in these genes, the methylation status of genes was analyzed by nMS-PCR. For PDGF, as presented in Fig. 2A, the methylation status of PDGF is increased, particularly, in the $100 \mu \mathrm{M}$ Hcy group, in which it was increased 7.6-fold, compared with the untreated group $(\mathrm{P}<0.01)$. For $\mathrm{p} 53$, as presented in Fig. $2 \mathrm{~B}$, p53 methylation levels were increased in a dose-dependent manner with the Hcy concentration. For PTEN and MFN2, the methylation levels were elevated by treatment with Hcy 

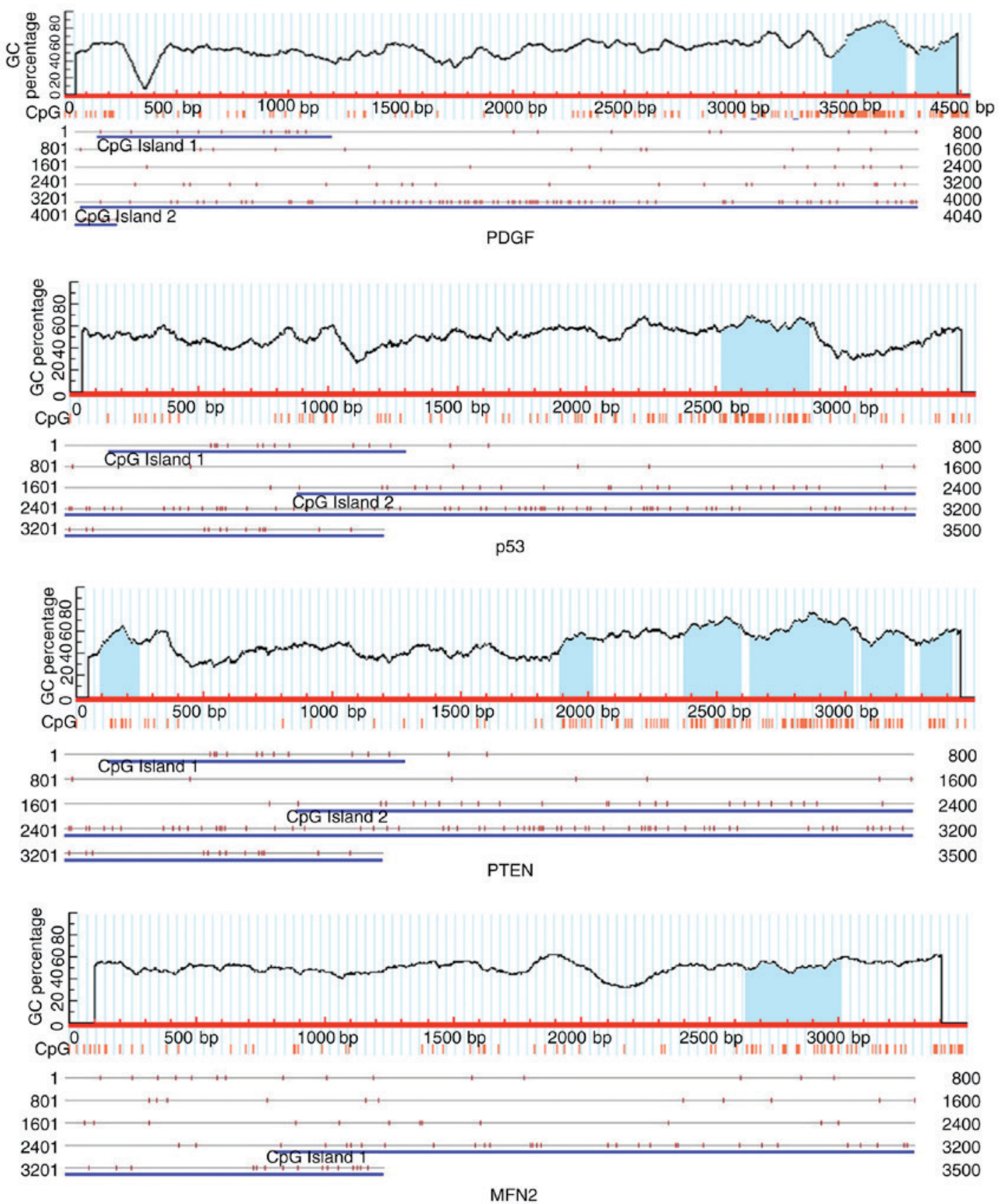

Figure 1. The bioinformatics analysis of promoters in PDGF, P53, PTEN and MFN2. The properties of CpG islands in the proximal region of the PDGF promoter were examined using the $\mathrm{CpG}$ Island Search engine (www.urogene.org/cgi-bin/methprimer/methprimer.cgi). At least one CpG island exists in the promoter region in all of the four genes. The light blue regions and the blue lines represent the CpG islands. PDGF, platelet-derived growth factor; PTEN, phosphatase and tensin homologue on chromosome 10; MFN2, mitofusin 2.

(Fig. 2C and D), however, it was not dose-dependent. Notably, the most marked effect was observed in the $100 \mu \mathrm{M}$ group. When treated with folate, the methylation levels of PDGF, PTEN and MFN2 were decreased compared with that of the $100 \mu \mathrm{M}$ group $(\mathrm{P}<0.05)$.

It was known that Hcy impacted the gene-specific methylation, however it remained unclear whether it affected the global methylation status, Alu and LINE-1 methylation status is considered as a good indicator of global methylation (21), thus these methylation levels were detected in VSMCs treated by Hcy. The results indicated that both Alu and LINE-1 were in a hypo-methylated state (Fig. $2 \mathrm{E}$ and $\mathrm{F}$; $\mathrm{P}<0.01$ ). No significant difference was observed in $100 \mu \mathrm{M}$ group, however the results in the $50 \mu \mathrm{M}$ group were significant. In addition, the folate group exhibited an antagonistic effect $(\mathrm{P}<0.05)$.

AZC, an inhibitor of DNA methylation, was added, and co-incubated VSMCs were treated with different concentrations of Hcy, then the methylation levels of Alu and Line-1 were measured with nMS-PCR. When compared with untreated cells, the methylation levels of Alu and Line-1 were suppressed in the Hcy treated groups. These data indicated that Hcy impacted the methylation status of these genes and that this may contribute to the proliferation of VSMCs induced by Hcy.

PDGF, P53,PTENandMFN2 expression levels in Hcy-treated $V S M C s$. It was identified that Hcy affected the methylation 
A

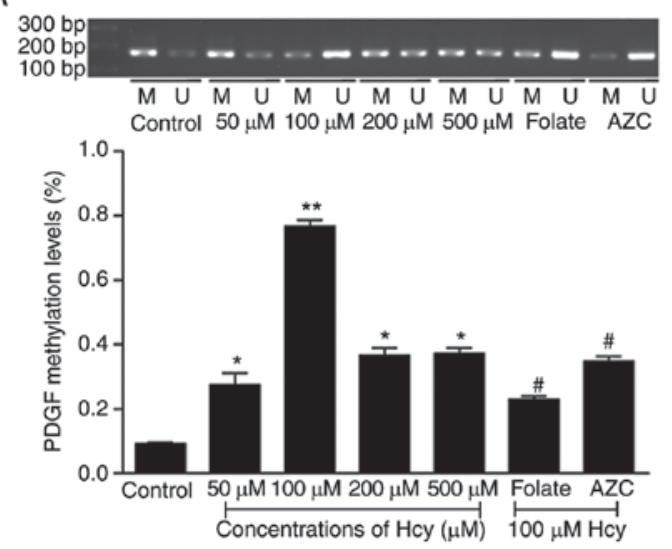

C
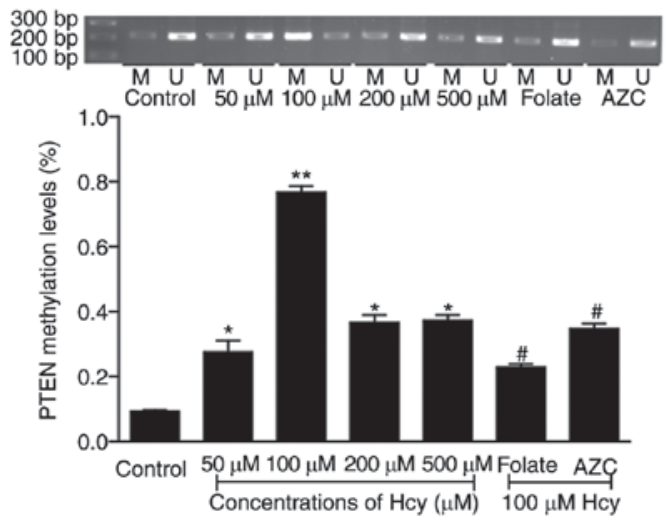

E
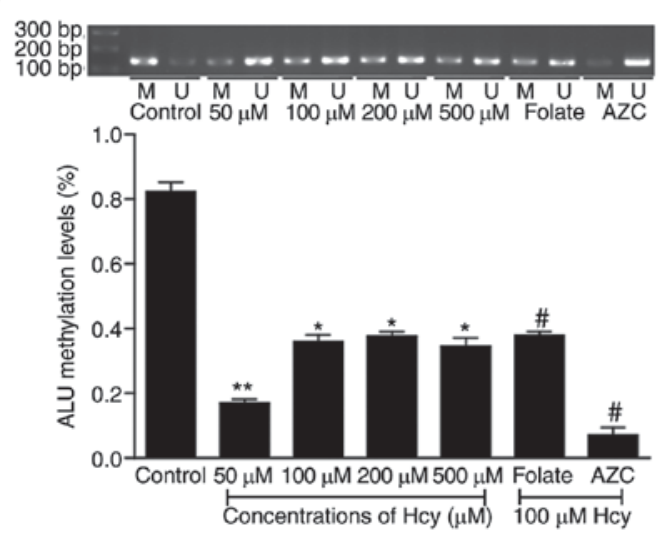

B

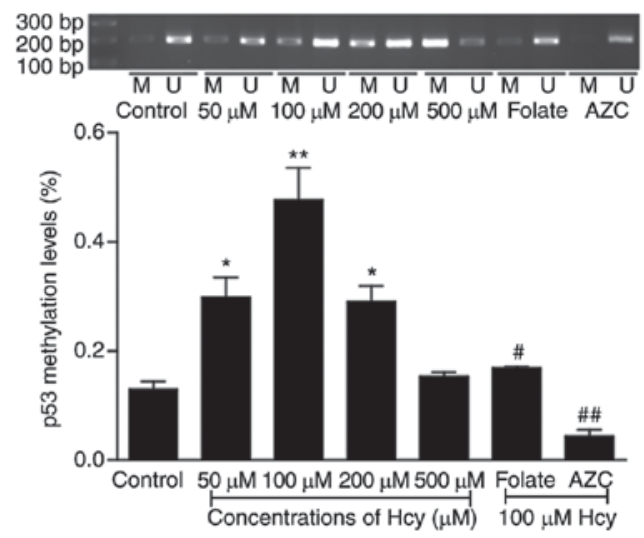

D

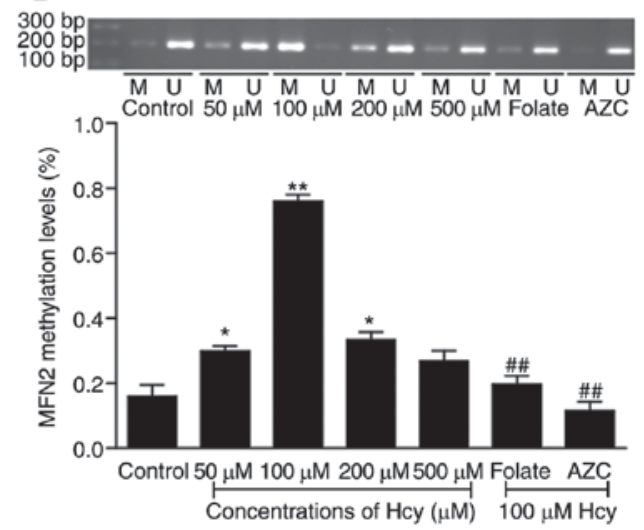

F

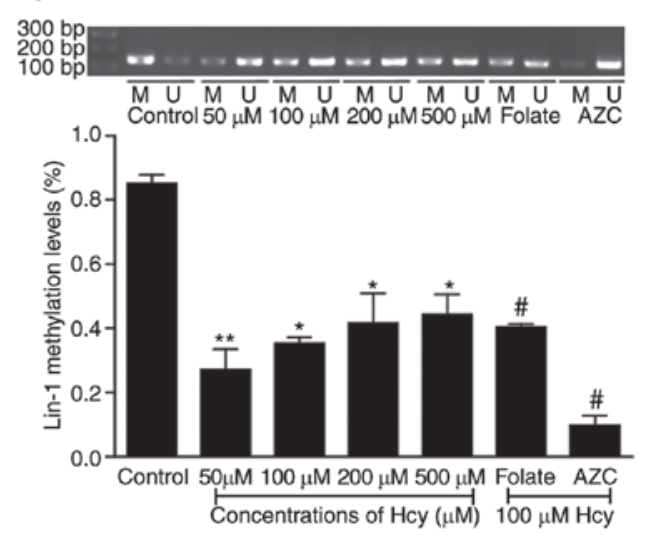

Figure 2. The methylation levels of PDGF, P53, PTEN, MFN2, Alu and Line-1. The methylation status was detected in VSMCs treated with different concentrations of Hcy by nMS-PCR. (A) The methylation of PDGF was detected by nMS-PCR in VSMCs, following co-incubation with different concentrations of Hcy for $72 \mathrm{~h}$; (B) The methylation of P53 was detected by nMS-PCR in VSMCs, following co-incubation with different concentrations of Hcy for 72 h; (C) The methylation of PTEN was detected by nMS-PCR in VSMCs, following co-incubated with different concentrations of Hcy for 72 h; (D) The methylation of MFN2 was detected by nMS-PCR in VSMCs, following co-incubation with different concentrations of Hcy for 72 h; (E) The methylation of Alu was detected by nMS-PCR in VSMCs, following co-incubation with different concentrations of Hcy for 72 h; (F) The methylation of Line-1 was detected by nMS-PCR in VSMCs, following co-incubation with different concentrations of Hcy for $72 \mathrm{~h}$. M, methylation; U, unmethylated; Folate group, $30 \mu \mathrm{M}$ folate in $100 \mu \mathrm{M}$ Hcy; AZC group, $5 \mu \mathrm{M}$ AZC in $100 \mu \mathrm{M}$ Hcy. Data are presented as the mean \pm standard deviation from 3 independent experiments performed in triplicate. ${ }^{*} \mathrm{P}<0.05$, ${ }^{* *} \mathrm{P}<0.01$, vs. the control group; ${ }^{\#} \mathrm{P}<0.05,{ }^{\# \#} \mathrm{P}<0.01$, vs. the $100 \mu \mathrm{M}$ Hcy group. PDGF, platelet-derived growth factor; PTEN, phosphatase and tensin homologue on chromosome 10; MFN2, mitofusin 2; Alu, alumninium; Line-1, long interspersed nucleotide element-1; nMS-PCR, nested methylation-specific-polymerase chain reaction; VSMCs, vascular smooth muscle cells; Hcy, homocysteine; AZC, 5-aza-2'-deoxycytidine.

levels of genes, however whether this further impacted the expression remained unclear. In order to investigate whether this occurred in VSMCs treated by Hcy, the mRNA and protein levels of the genes were assayed by RT-qPCR and western blotting. As presented in Fig. 3A, PDGF mRNA and protein expression levels were increased in a dose-dependent manner. p53, PTEN and MFN2 were decreased in the 50,
100, 200 and $500 \mu \mathrm{M}$ Hcy groups (Fig. 3B-D). The expression levels of p53, PTEN and MFN2 consistently exhibited the greatest effects in the $100 \mu \mathrm{M}$ group. In addition, more folate suppressed the changes induced by Hcy. When treated with AZC, the antagonist of DNA methylation, the expression of PDGF, p53, PTEN and MFN2 increased significantly $(\mathrm{P}<0.05)$. These data suggested that Hcy affected the 

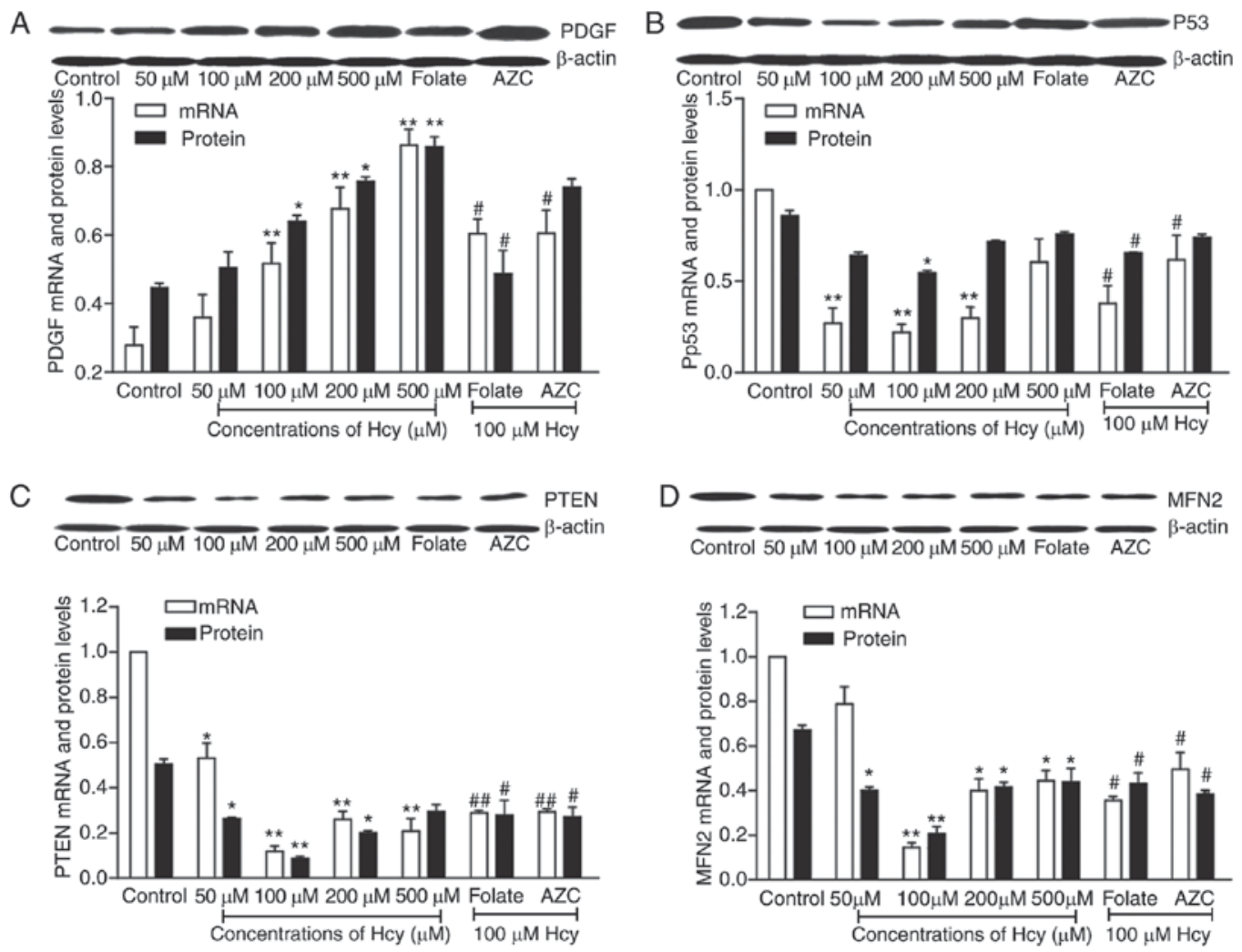

Figure 3. The expression of PDGF, P53, PTEN and MFN2 in Hcy-treated VSMCs. VSMCs were exposed to 0, 50, 100, 200 and $500 \mu \mathrm{M}$ of Hcy for $72 \mathrm{~h}$, mRNA and protein were extracted from VSMCs and detected by reverse transcription-quantitative polymerase chain reaction and western blotting, respectively. Expression levels of (A) PDGF, (B) p53, (C) PTEN and (D) MFN2 in VSMCs co-incubated with Hcy for $72 \mathrm{~h}$ are presented. Folate group, $30 \mu \mathrm{M}$ folate in $100 \mu \mathrm{M}$ Hcy; AZC group, $5 \mu \mathrm{M}$ AZC in $100 \mu \mathrm{M}$ Hcy Data are presented as the mean \pm standard deviation from 3 independent experiments performed in triplicates. ${ }^{*} \mathrm{P}<0.05$ and ${ }^{* *} \mathrm{P}<0.01$, vs. the control group; ${ }^{\#} \mathrm{P}<0.05$ and ${ }^{\# \#} \mathrm{P}<0.01$, vs. the $100 \mu \mathrm{M}$ Hcy group. PDGF, platelet-derived growth factor; PTEN, phosphatase and tensin homologue on chromosome 10; MFN2, mitofusin 2; Hcy, homocysteine; VSMCs, vascular smooth muscle cells.

expression of the genes, which may be involved in the DNA methylation process.

SAM and SAH levels in VSMCs treated with Hcy. Similar to Hcy, SAM and SAH are intermediates in the methionine metabolism, and are important factors in the transmethylation process (22). The SAM and SAH levels were measured using HPLC in the VSMCs, which were treated with Hcy. As presented in Fig. 4, the results demonstrated that the intracellular levels of SAH were significantly increased, compared with the control group, while the concentrations of SAM and the ratio of SAM/SAH were decreased, when Hcy concentrations increased $(\mathrm{P}<0.05$; Fig. 4). SAH levels increased and SAM levels decreased $(\mathrm{P}<0.05)$, when VSMCs were treated with Hcy.

\section{Discussion}

VSMCs are major components of the arterial wall, and abnormal proliferation of VSMCs serves a pivotal role in the pathogenesis of AS (23). As an important independent risk factor of AS, Hcy stimulated the VSMCs proliferation, which was identified in previous studies $(6,24)$. Cellular proliferation is associated with the regulation of key genes. Thus in the present study, 4 genes were selected for analysis; PDGF, p53, PTEN and MFN2. PDGF is a potent mitogen, which serves crucial roles in developmental and physiological processes, in addition to being directly implicated in proliferative disorders, and it is a potent stimulator of VSMC growth (25). p53 is a key tumor suppressor and a key regulator of various signaling pathways, including cell-cycle regulation, induction of apoptosis, development and differentiation (26). In vivo, p53 expression is negatively correlated with markers of cell proliferation in human atherosclerosis; adenoviral expression of p53 reduces cellular proliferation in the rat carotid artery (27), and by contrast, siRNA of p53 increases cellular proliferation (28). In $\mathrm{p}^{-1-} / \mathrm{ApoE}^{-/}$mice, $\mathrm{p} 53$ have been demonstrated to increase aortic plaque formation, with increased rates of cell proliferation and reduced rates of apoptosis in brachiocephalic artery plaques (29). PTEN is well known tumor suppressor and is additionally involved in regulation of a variety of physiological and pathological processes, including cell proliferation, differentiation, apoptosis, adhesion and migration (30). PTEN was expressed endogenously in VSMCs, and overexpression of PTEN significantly inhibited basal and PDGF-mediated VSMC proliferation and migration (31). PTEN overexpression in VSMCs using adenoviral transfection resulted in inhibition of cell proliferation and migration induced by angiotensin II (32). MFN2 was first cloned from VSMCs in spontaneous hypertensive rats using the differential display technique (33), which restrained the proliferation of VSMCs mediated by inhibition of extracellular signal-related kinase/mitogen-activated protein kinase signaling and subsequent cell-cycle arrest. The expression changes of these key 


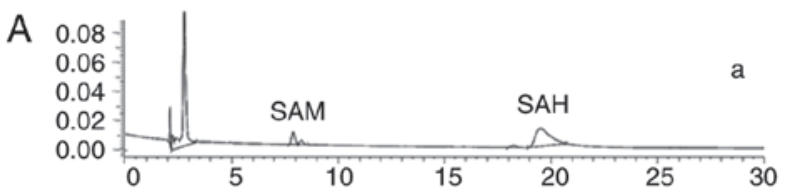

B
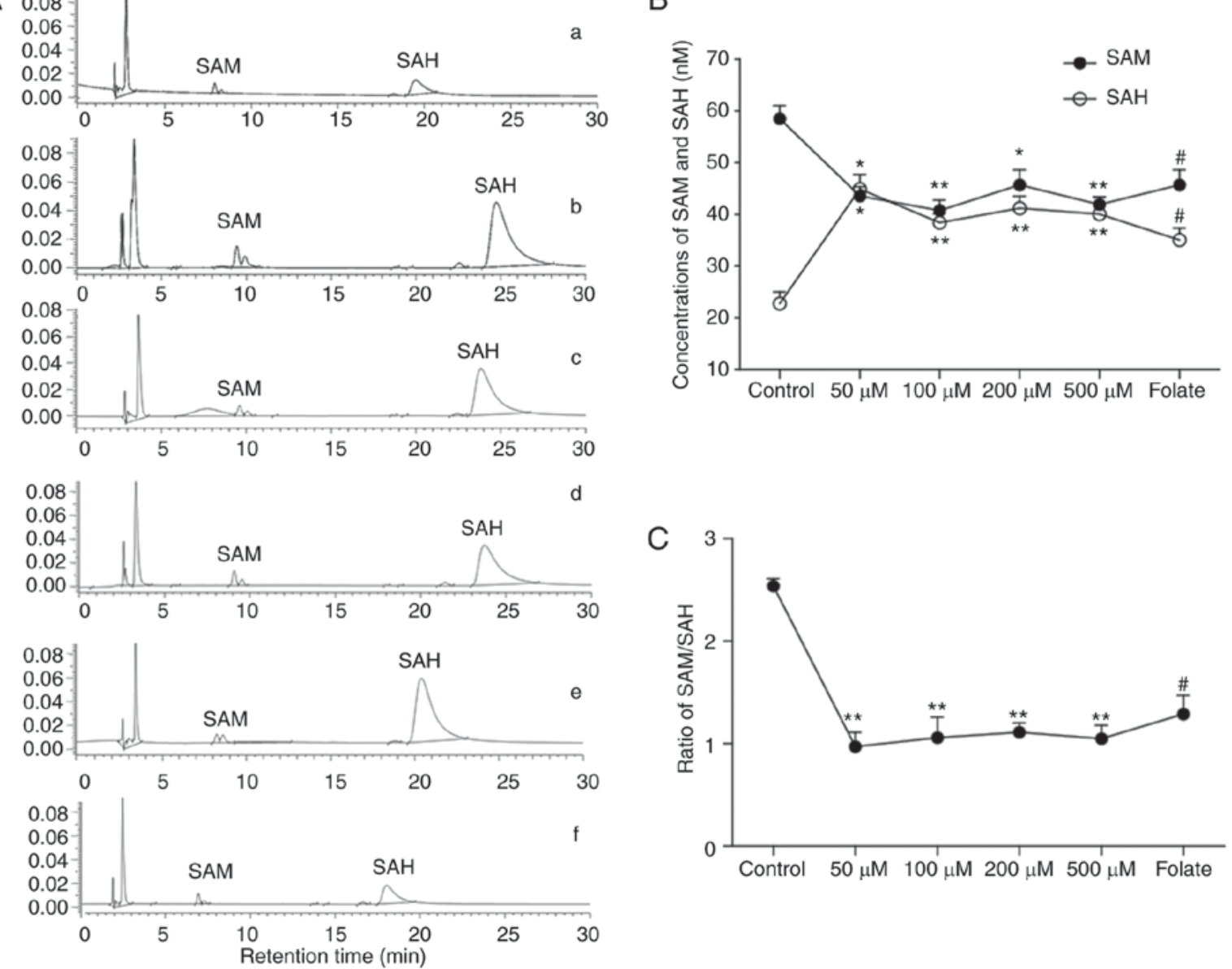

Figure 4. The SAM and SAH levels in VSMCs treated by Hcy. (A) A chromatogram of SAH and SAM of all groups detected by high-performance liquid chromatography, chromatograms were recorded by an integrator. a, Untreated group; b, $50 \mu \mathrm{M}$ Hcy group; c, $100 \mu \mathrm{M}$ Hcy group; d, $200 \mu \mathrm{M}$ Hcy group; e, $500 \mu \mathrm{M}$ Hcy group; and f, folate group. (B) The concentrations of SAM and SAH in VSMCs. (C) The ratio of SAH and SAH in VSMCs. Folate group, $30 \mu \mathrm{M}$ folate in $100 \mu \mathrm{M} \mathrm{Hcy}$. The data were obtained using automatic peak area integration. Data are presented mean \pm standard deviation from 3 independent experiments performed in triplicate. ${ }^{*} \mathrm{P}<0.05$ and ${ }^{* *} \mathrm{P}<0.01$, vs. the control group; ${ }^{*} \mathrm{P}<0.05$ vs. the $100 \mu \mathrm{M}$ Hcy group. SAM, S-adenosylmethionine; SAH, S-adenosylhomocysteine; VSMCs, vascular smooth muscle cells; Hcy, homocysteine.

genes may involve in the imbalance of cell proliferation. The present study indicated an elevation of PDGF, and a reduction of p53, PTEN and MFN2 in VSMCs treated with Hcy, which indicated that Hcy impacted the expression of these genes and resulted in the proliferation of VSMCs.

DNA methylation is an important epigenetic modification at the transcriptional level, which commonly occurs at the $\mathrm{CpG}$ dinucleotides of gene promoter regions, particularly in the promoter-associated $\mathrm{CpG}$ islands (34). Consistent with these important roles, a growing number of human diseases have been identified to be associated with aberrant DNA methylation. In the present study, $\mathrm{CpG}$ islands were searched for in the promoters of the selected genes, PDGF, p53, PTEN and MFN2, using two $\mathrm{CpG}$ island search engines. It was identified that at least one $\mathrm{CpG}$ island exists in the promoter regions of all 4 genes. In the promoter region of PTEN, 6 CpG islands were identified, which indicated that they have potential to be modified by DNA methylation and regulate their expression.

It was previously reported that Hcy caused cell-type-specific hypomethylation in endothelial cells, VSMCs and foam cells (35) and it was hypothesized that Hcy metabolism and methylation may be associated, resulting in tissue-specific pathology in AS. In addition,
DNA methylation also impacts the selected genes PDGF, p53, PTEN and MFN2. In the present study, the key genes associated with cell proliferation regulation were selected in order to investigate the methylation changes in the single VSMCs. In the VSMCs treated with Hcy, hypermethylation or hypomethylation was observed to occur in the promoters of the selected genes, of which PDGF was hypomethylated and p53, PTEN, MFN2 were hypermethylated. Furthermore, the expression levels were altered from normal to aberrant levels. When treated with AZC, an antagonist of DNA methylation, both the methylation status and the expression of the four genes was altered. These results demonstrate that Hcy affected the expression of the genes, which may be involved in the DNA methylation process.

In order to try to confirm the methylation status characteristics in the VSMCs affected by Hcy, we detected global methylation levels were measured. In general, Alu and LINE-1 elements are methylated in somatic tissues, however are hypomethylated in human cancer (36). In the present study, Hcy was observed to reduce the methylation levels of Alu and LINE-1. In the VSMCs, Hcy not only affected the methylation levels of particular genes, however additionally impacted the global methylation status. Hcy-associated methylation changes 
are also suggested as a biomarker for use in the prevention and therapy of AS in the future.

In the methionine cycle, SAM is the key methyl donor for cellular methylation events including DNA methylation, and this process produces SAH. SAH is converted to Hcy in a reversible reaction, and elevated levels of $\mathrm{SAH}$ and concomitant increases in the SAH/SAM ratio are suggested to inhibit cellular methylation reactions (37). The present study observed an increase of SAM and a decrease in the SAM/SAH ratio, which demonstrated that Hcy amassment accumulated in the methionine cycle, and caused the SAM, $\mathrm{SAH}$ and SAM/SAH ratio changes, then affected methylation process. Furthermore, in the cycle, folate is integrally involved in both substrate synthesis and product removal via its role in methionine synthesis from Hcy. Folate insufficiency leads to a decrease in SAM synthesis (38), which may compromise SAM-dependent methylation reactions, however additionally also leads to an increase in cellular concentrations of SAH by promoting Hcy accumulation via reversal of SAH hydrolase. In the present study, folate was added to reduce the Hcy effect. The results indicated an antagonistic effect against Hcy both in the methylation levels and in the gene expression levels. These data indicated that Hcy may impact the methylation status partly through the methionine cycle.

In conclusion, Hcy impacted the methylation status of the genes involved in the cell proliferation, leading to a loss of cellular control in VSMCs, and induced the proliferation of VSMCs. Hcy not only affected the methylation levels of special genes, however additionally impacted the global methylation status, which may be a characteristic of VSMCs treated with Hcy. The data provided evidence for the mechanisms of VSMC proliferation in AS induced by Hcy and may provide a potential diagnostic marker for AS induced by Hcy.

\section{References}

1. Devasia AJ, Joy B and Tarey SD: HSerum homocysteine as a risk factor for carotid intimal thickening in acute stroke: A cross sectional observational study. Ann Indian Acad Neurol 19: 48-51, 2016.

2. Liu K, Xuekelati S, Zhang Y, Yin Y, Li Y, Chai R, Li X, Peng Y, $\mathrm{Wu} \mathrm{J}$ and Guo X: Expression levels of atherosclerosis-associated miR-143 and miR-145 in the plasma of patients with hyperhomocysteinaemia. BMC Cardiovasc Disord 17: 163, 2017.

3. Xiaoling Y, Li Z, ShuQiang L, Shengchao M, Anning Y, Ning D, Nan L, Yuexia J, Xiaoming Y, Guizhong L and Yideng J: Hyperhomocysteinemia in $\mathrm{ApoE}^{-/-}$Mice leads to overexpression of enhancer of Zeste homolog 2 via miR-92a regulation. PLoS One 11: e0167744, 2016.

4. Liu T, Lin J, Ju T, Chu L and Zhang L: Vascular smooth muscle cell differentiation to an osteogenic phenotype involves matrix metalloproteinase-2 modulation by homocysteine. Mol Cell Biochem 406: 139-149, 2015.

5. Liu X, Shen J, Zhan R, Wang X, Wang X, Zhang Z, Leng X, Yang Z and Qian L: Proteomic analysis of homocysteine induced proliferation of cultured neonatal rat vascular smooth muscle cells. Biochim Biophys Acta 1794: 177-184, 2009.

6. Han XB, Zhang HP, Cao CJ, Wang YH, Tian J, Yang XL, Yang AN, Wang J, Jiang YD and Xu H: Aberrant DNA methylation of the PDGF gene in homocysteine-mediated VSMC proliferation and its underlying mechanism. Mol Med Rep 10: 947-954, 2014

7. Taysi S, Keles MS, Gumustekin K, Akyuz M, Boyuk A, Cikman $\mathrm{O}$ and Bakan N: Plasma homocysteine and liver tissue $\mathrm{S}$-adenosylmethionine, $\mathrm{S}$-adenosylhomocysteine status in vitamin B6-deficient rats. Eur Rev Med Pharmacol Sci 19: 154-160, 2015.
8. Elshorbagy AK, Jernerén F, Samocha-Bonet D, Refsum H and Heilbronn LK: Serum S-adenosylmethionine, but not methionine, increases in response to overfeeding in humans. Nutr Diabetes 6: e192, 2016.

9. Wang L, Fu X, Peng X, Xiao Z, Chen G and Wang X: DNA methylation profiling reveals correlation of differential methylation patterns with gene expression in human epilepsy. J Mol Neurosci 59: 68-77, 2016.

10. Mandaviya PR, Stolk L and Heil SG: Homocysteine and DNA methylation: A review of animal and human literature. Mol Genet Metab 113: 243-252, 2014.

11. Yang AN, Zhang HP, Sun Y, Yang XL, Wang N, Zhu G, Zhang H, $\mathrm{Xu} \mathrm{H}$, Ma SC, Zhang Y, et al: High-methionine diets accelerate atherosclerosis by HHcy-mediated FABP4 gene demethylation pathway via DNMT1 in ApoE(-/-) mice. FEBS Lett 589: 3998-4009, 2015.

12. Yideng J, Zhihong L, Jiantuan X, Jun C, Guizhong L and Shuren W: Homocysteine-mediated PPARalpha,gamma DNA methylation and its potential pathogenic mechanism in monocytes. DNA Cell Biol 27: 143-150, 2008.

13. Jiang Y, Zhang J, Xiong J, Cao J, Li G and Wang S: Ligands of peroxisome proliferator-activated receptor inhibit homocysteine-induced DNA methylation of inducible nitric oxide synthase gene. Acta Biochim Biophys Sin (Shanghai) 39: 366-376, 2007.

14. Greißel A, Culmes M, Napieralski R, Wagner E, Gebhard H, Schmitt M, Zimmermann A, Eckstein HH, Zernecke A and Pelisek J: Alternation of histone and DNA methylation in human atherosclerotic carotid plaques. Thromb Haemost 114: 390-402, 2015.

15. Zhang HP, Wang YH, Cao CJ, Yang XM, Ma SC, Han XB, Yang XL, Yang AN, Tian J, Xu H, et al: A regulatory circuit involving miR-143 and DNMT3a mediates vascular smooth muscle cell proliferation induced by homocysteine. Mol Med Rep 13: 483-490, 2016.

16. Ma S, Zhang H, Sun W, Gong H, Wang Y, Ma C, Wang J, Cao C, Yang X, Tian J and Jiang Y: Hyperhomocysteinemia induces cardiac injury by up-regulation of p53-dependent Noxa and Bax expression through the p53 DNA methylation in ApoE(-/-) mice. Acta Biochim Biophys Sin (Shanghai) 45: 391-400, 2013.

17. Livak KJ and Schmittgen TD: Analysis of relative gene expression data using real-time quantitative PCR and the 2(-Delta Delta C(T)) method. Methods 25: 402-408, 2001.

18. How-Kit A, Daunay A, Mazaleyrat N, Busato F, Daviaud C, Teyssier E, Deleuze JF, Gallusci P and Tost J: Accurate CpG and non-CpG cytosine methylation analysis by high-throughput locus-specific pyrosequencing in plants. Plant Mol Biol 88: 471-485, 2015.

19. Camacho-Arroyo I, Hansberg-Pastor V and Rodríguez-Dorantes M: DNA methylation analysis of steroid hormone receptor genes. Methods Mol Biol 1165: 89-98, 2014.

20. Chatterjee R and Vinson C: CpG methylation recruits sequence specific transcription factors essential for tissue specific gene expression. Biochim Biophys Acta 1819: 763-770, 2012.

21. Pramio DT, Pennacchi PC, Maria-Engler SS, Campos AH, Duprat JP, Carraro DM and Krepischi AC: LINE-1 hypomethylation and mutational status in cutaneous melanomas. J Investig Med 64: 899-904, 2016.

22. Zhang H, Liu Z, Ma S, Zhang H, Kong F, He Y, Yang X, Wang Y, Xu H, Yang A, et al: Ratio of S-adenosylmethionine to S-adenosylhomocysteine as a sensitive indicator of atherosclerosis. Mol Med Rep 14: 289-300, 2016.

23. Qi L, Zhi J, Zhang T, Cao X, Sun L, Xu Y and Li X: Inhibition of microRNA-25 by tumor necrosis factor $\alpha$ is critical in the modulation of vascular smooth muscle cell proliferation. Mol Med Rep 11: 4353-4358, 2015.

24. Meng L, Longbin L, Zhou C, Pan S, Zhai X, Jiang C, Guo Y, Ji Z, Chi J, Peng F and Guo H: Polyphenols and Polypeptides in Chinese rice wine inhibit homocysteine-induced proliferation and migration of vascular smooth muscle cells. J Cardiovase Pharmacol 67: 482-490, 2016.

25. Shin SY, Jung JY, Yong Y, Cho HJ, Lim Y and Lee YH: Inhibition of PDGF-induced migration and TNF $\alpha$-induced ICAM-1 expression by maltotetraose from bamboo stem extract (BSE) in mouse vascular smooth muscle cells. Mol Nutr Food Res 60: 2086-2097, 2016.

26. Jain AK, Allton K, Iacovino M, Mahen E, Milczarek RJ, Zwaka TP, Kyba M and Barton MC: p53 regulates cell cycle and microRNAs to promote differentiation of human embryonic stem cells. PLoS Biol 10: e1001268, 2012. 
27. Varela A,Piperi C, Sigala F, Agrogiannis G, Davos CH, Andri MA Manopoulos C, Tsangaris S, Basdra EK and Papavassiliou AG: Elevated expression of mechanosensory polycystins in human carotid atherosclerotic plaques: Association with p53 activation and disease severity. Sci Rep 5: 13461, 2015.

28. Shan X, Fu YS, Aziz F, Wang XQ, Yan Q and Liu JW: Ginsenoside Rg3 inhibits melanoma cell proliferation through down-regulation of histone deacetylase 3 (HDAC3) and increase of p53 acetylation. PLoS One 9: e115401, 2014.

29. Sun GB, Qin M, Ye JX, Pan RL, Meng XB, Wang M, Luo Y, Li ZY, Wang HW and Sun XB: Inhibitory effects of myricitrin on oxidative stress-induced endothelial damage and early atherosclerosis in ApoE $^{-/-}$mice. Toxicol Appl Pharmacol 271: 114-126, 2013.

30. Zhang LY, Ho-Fun Lee V, Wong AM, Kwong DL, Zhu YH, Dong SS, Kong KL, Chen J, Tsao SW, Guan XY and Fu L: MicroRNA-144 promotes cell proliferation, migration and invasion in nasopharyngeal carcinoma through repression of PTEN. Carcinogenesis 34: 454-463, 2013.

31. Hu C, Liu S, Sun Y, Shi G and Li Y: Effect of recombinant hPTEN gene expression on PDGF induced VSMC proliferation. Cell Biochem Biophys 70: 1185-1190, 2014.

32. Chen WJ, Pang JH, Lin KH, Lee DY, Hsu LA and Kuo CT: Propylthiouracil, independent of its antithyroid effect, promotes vascular smooth muscle cells differentiation via PTEN induction. Basic Res Cardiol 105: 19-28, 2010.
33. Shu Z, Yu M, Zeng G, Zhang X, Wu L and Tan X: Epigallocatechin-3-gallate inhibits proliferation of human aortic smooth muscle cells via up-regulating expression of mitofusin 2 . Eur J Cell Biol 93: 137-144, 2014.

34. Vogel Ciernia A and LaSalle J: The landscape of DNA methylation amid a perfect storm of autism aetiologies. Nat Rev Neurosci 17: 411-423, 2016.

35. Liang Y, Yang X, Ma L, Cai X, Wang L, Yang C, Li G, Zhang M, Sun W and Jiang Y: Homocysteine-mediated cholesterol efflux via ABCA1 and ACAT1 DNA methylation in THP-1 monocyte-derived foam cells. Acta Biochim Biophys Sin (Shanghai) 45: 220-228, 2013.

36. Yüksel S, Kucukazman SO, Karatas GS, Ozturk MA, Prombhul S and Hirankarn N: Methylation Status of Alu and LINE-1 interspersed repetitive sequences in Behcet's disease patients. Biomed Res Int 2016: 1393089, 2016.

37. Zhang J and Zheng YG: SAM/SAH analogs as versatile tools for SAM-Dependent Methyltransferases. ACS Chem Biol 11: 583-597, 2016.

38. Howe CG, Niedzwiecki MM, Hall MN, Liu X, Ilievski V, Slavkovich V, Alam S, Siddique AB, Graziano JH and Gamble MV: Folate and cobalamin modify associations between $\mathrm{S}$-adenosylmethionine and methylated arsenic metabolites in arsenic-exposed Bangladeshi adults. J Nutr 144: 690-697, 2014. 